\title{
Brief Report: Physical health of adolescent perpetrators of sibling aggression
}

\author{
Corinna Jenkins Tucker, Ph.D. ${ }^{\mathrm{ab}}$, Karen Van Gundy, Ph.D. ${ }^{\mathrm{bc}}$, Erin Hiley Sharp, Ph.D. ${ }^{\text {ab }}$, and \\ Cesar Rebellon, Ph.D. ${ }^{\text {bc }}$
}

${ }^{\mathrm{a}}$ Department of Human Development and Family Studies, University of New Hampshire, Durham, New Hampshire

${ }^{b}$ The Carsey School of Public Policy, University of New Hampshire, Durham, New Hampshire 'Sociology Department, University of New Hampshire, Durham, New Hampshire

We are grateful to the youth, school personnel, and communities who participated in this project. We thank our team members Drs. Eleanor Jaffee and Meghan Mills, Mr. Michael Stanton, and a group of graduate and undergraduate students. This study was supported by the National Science Foundation (\#155797), the Neil and Louise Tillotson Fund of the New Hampshire Charitable Foundation, and the Carsey School of Public Policy at the University of New Hampshire.

Address correspondence to: Corinna Jenkins Tucker, Ph.D., 309 Pettee Hall, Department of Human Development and Family Studies, University of New Hampshire, Durham, NH 03824. Email address: cjtucker@unh.edu. 


\begin{abstract}
We describe adolescents' perpetration of sibling aggression and its link to physical health two years later. In-school surveys at Time $1(N=331)$ and Time 2 (two-years later, $N=283$ ) were administered to adolescents (at Time $1, M_{\text {age }}=15.71$ years, $S D=.63 ; 52 \%$ female) living in the United States querying about perpetration of aggression toward a sibling closest in age and perceived physical health. The majority of adolescents perpetrated aggression towards their sibling (74\%). Adolescents who were part of brother-brother pairs reported the most aggression. Hierarchical regression analysis showed that perpetrating sibling aggression more often at Time 1 was predictive of lower physical health at Time 2 controlling for Time 1 physical health and demographic characteristics. Perpetration of aggression toward a sibling is common and has negative health consequences in late adolescence suggesting this issue should be targeted to improve adolescents' sibling dynamics and physical health.
\end{abstract}

Keywords: Siblings; perpetrator; aggression; physical health 
Sibling aggression is the most common form of family violence (Straus, Gelles, \& Steinmetz (1980/2006). Given that $78 \%$ of children live with at least one sibling in the United States (Kreider \& Ellis, 2011) and the importance of sibling interactions for well-being (Buist, Deković, \& Prinzie, 2013), sibling aggression is surprisingly rarely studied. Sibling aggression peaks in the school-aged years and decreases across adolescence but becomes more severe with victims reporting increased rates of object or weapon use and injuries (Tucker, Finkelhor, Shattuck, \& Turner, 2013). Existing research on sibling aggression tends to focus on frequency of victimization and consequences for young children's mental health. A few studies have established that the majority of adolescents have perpetrated some form of aggression against their sibling (Roscoe, Goodwin, \& Kennedy, 1987; Wolke \& Samara, 2004). A significant contribution of the current study is our investigation of how adolescents' perpetration of sibling aggression is associated with their physical health two years later in late adolescence.

Although siblings spend less time together in adolescence than in childhood, they continue to play an important and influential role in adolescents' lives and mental health (e.g., Buist et al., 2013). Research demonstrates that children's aggressive behavior is associated with lower mental health (Crick, Ostrov, \& Werner, 2006) and developing later health problems (Temcheff, Serbin, Martin-Storey, Stack, Ledingham, \& Schwartzman, 2011). Perpetration of aggressive behavior usually involves stressful or challenging situations. Exposure to stress depletes emotional and physical resources that can lead to lower immunity and vulnerability to a range of health issues. It is likely that aggressive behavior toward a sibling, another form of childhood aggression, will have health implications too. One study has shown that parents' sanctioning of aggressive behavior between siblings (e.g., encouraging siblings to hit, kick, bite or push) was linked concurrently to school-aged children's worse physical health (Tucker \& 
Kazura, 2013). Although adolescence is generally one of the healthiest times of life, health problems are likely to result from psychosocial rather than biological causes (Ozer \& Irwin, 2009) and can affect the ways adolescents spend their time and their familial and extra-familial relationships. An additional contribution of the current study is that it will extend the current literature on sibling aggression, characterized by cross-sectional designs, through an analysis of longitudinal data showing the short-term implications of perpetration of aggression for adolescent physical health.

\section{Methods}

At Time 1 , a population of $10^{\text {th }}$ graders $\left(M_{\text {age }}=15.71\right.$ years, $S D=.63 ; 52 \%$ female $)$ attending all 16 public schools in five school districts in a rural northern New England county completed self-reported paper-and-pencil questionnaires $(\mathrm{N}=331 ; 77 \%$ response rate). At Time 1, 302 adolescents reported on a sibling and the average age distance between siblings was 3.66 years $(S D=2.77)$. At Time 2 , two years later, respondents completed a second in-school survey ( $\mathrm{N}=283 ; 85 \%$ follow-up rate). Adolescents who dropped out at Time 2 were more likely to be male; there were no variations by parent education, ethnicity or aggression perpetration. We obtained passive parent consent, and students were informed that the survey was voluntary and confidential. Each participant received a \$10 gift card.

At Time 1, perpetration of aggression was assessed by a four-item scale that was informed by previous research on sibling aggression and adapted from other aggression scales. Items queried about the frequency of threatening, hitting, using physical force and hurting a sibling closest in age (Cronbach's alpha $=.90)$. At Time 1 and 2, adolescents' physical health was measured by whether the adolescent had eight physical symptoms (e.g., felt like vomiting, had trouble sleeping, have headaches, feel really sick; NICHD Early Childcare Research 
Network, 2005). Positive responses were counted and summed so that higher scores indicate worse health (at Time $1, M=5.20, S D=1.69$, range $0-8$, and at Time $2, M=4.93, S D=1.97$, range $0-8)$.

Descriptive statistics were calculated for the total and each item of the aggression scale. A one-way ANOVA examined sibling gender composition differences in perpetration of sibling aggression with follow-up Tukey tests. Hierarchical regression was conducted to examine the relationship between perpetration and physical health two years later controlling for health at Time 1 and other demographic variables.

\section{Results}

Table 1 summarizes the frequency with which adolescents engaged in total and in each act of sibling aggression by gender composition of the sibling dyad. In brief, the majority of adolescents (74\%) reported perpetrating aggressive acts toward their closest in age sibling. The most common act of aggression was hitting. Each item of the measure and the overall score of perpetration of aggression differed by gender composition of the sibling dyad. The overall prevalence of perpetration was highest among brother-brother sibling pairs compared to the other three sibling gender combinations. None of the other pairs differed from one another. Table 2 shows that, with statistical adjustments for prior health and demographic variables, perpetration of sibling aggression was predictive of worse physical health (i.e., greater number of physical symptoms) two years later in late adolescence. Additional exploratory analysis showed that gender composition of the sibling dyad did not moderate the relationship between perpetration of sibling aggression and physical health two years later. Other analyses indicated that physical health was not predictive sibling aggression two years later suggesting the direction of effects.

\section{Discussion}


Sibling aggression is estimated to occur in the majority of U.S. families (Straus et al., 1986/2006) but society has been slow to recognize sibling aggression as problematic. In this study, similar to previous research, the majority of adolescents perpetrated aggression (Roscoe et al., 1987; Wolke \& Samara, 2004) toward their sibling closest in age and perpetration was highest in brother-brother pairs (Tucker et al., 2013). Recent research has called attention to sibling aggression and its connections to mental health (Caffaro, 2014). Our study is the first to show the implications of perpetrating aggression against a sibling for adolescents' physical health over a two-year period. Perpetration of aggression toward a sibling likely alters adolescents' physiological functioning due to the stressful nature of these interactions and leads to more health complaints. A limitation of this study includes self-reported data which has the potential to inflate the connection we found due to shared method variance. However, adolescents' self-reports may provide the most accurate reports of sibling interactions and health because parents are not aware of every sibling interaction and physical symptoms. This study would have been strengthened by the inclusion of sibling reports which would have enabled us to examine the extent of reciprocity in siblings' aggressive behaviors. Our work highlights the importance of practitioners helping families differentiate between aggressive sibling behavior that includes acts like threatening and hitting and sibling conflict that is characterized by negotiation and resolution and is associated with greater well-being (Tucker \& Kazura, 2013). Adolescent health is influenced by many factors but changing the nature of siblings' interactions with one another will contribute to improved adolescent well-being and likely benefit youth in many areas of their lives. 
Table 1

Mean (and standard deviation) of adolescents' perpetration of aggression toward their sibling by gender composition of the sibling dyad.

\begin{tabular}{lllll}
\hline Item & $\begin{array}{l}\text { SS } \\
(n=66)\end{array}$ & $\begin{array}{l}\text { SB } \\
(n=94)\end{array}$ & $\begin{array}{l}\text { BS } \\
(n=52)\end{array}$ & $\begin{array}{l}\text { BB } \\
(n=90)\end{array}$ \\
\hline Hit & $.89^{\mathrm{a}}(1.01)$ & $1.18^{\mathrm{a}}(1.13)$ & $.77^{\mathrm{a}}(1.20)$ & $1.61^{\mathrm{b}}(1.28)$ \\
Threaten & $.86^{\mathrm{a}}(.99)$ & $1.06^{\mathrm{ab}}(1.18)$ & $.85^{\mathrm{a}}(1.16)$ & $1.41^{\mathrm{b}}(1.40)$ \\
$\begin{array}{l}\text { Use physical } \\
\text { force }\end{array}$ & $.77^{\mathrm{a}}(.97)$ & $.98^{\mathrm{a}}(1.17)$ & $.81^{\mathrm{a}}(1.14)$ & $1.66^{\mathrm{b}}(1.45)$ \\
Hurt & $.73^{\mathrm{a}}(.95)$ & $.82^{\mathrm{a}}(1.07)$ & $.48^{\mathrm{a}}(.94)$ & $1.19^{\mathrm{b}}(1.24)$ \\
$\begin{array}{l}\text { Average of } 4 \\
\text { items }\end{array}$ & $.81^{\mathrm{a}}(.81)$ & $1.01^{\mathrm{a}}(.97)$ & $.73^{\mathrm{a}}(1.00)$ & $1.47^{\mathrm{b}}(1.19)$ \\
\hline $\begin{array}{l}\text { Note: } \text { Scale } 0-4 ; 0 \\
\text { brother-sister. } \mathrm{BB}=\end{array}$ & not at all; $4=$ almost all the time. SS= sister-sister. SB = sister-bother. BS $=$ \\
\end{tabular}


Table 2

Hierarchical Multiple Regression Analysis Predicting Adolescents' Physical Health at Time 2 from their Perpetration of Aggression Toward Their Sibling at Time 1 (final model shown)

\begin{tabular}{|c|c|c|}
\hline & \multicolumn{2}{|c|}{ Physical Health Time 2} \\
\hline & $\mathrm{B}$ & $\Delta R^{2}$ \\
\hline Step 1 & & $.24 * * *$ \\
\hline Parent education & -.07 & \\
\hline Sister-sister pairs & .14 & \\
\hline Sister-brother pairs & $.20 *$ & \\
\hline Brother-sister pairs & .01 & \\
\hline Ethnicity & .03 & \\
\hline Birth order & -.06 & \\
\hline Physical health Time 1 & $.38 * * *$ & \\
\hline
\end{tabular}

Step 2

$.26 * * * \quad .02 *$

Perpetration sibling $\quad .16^{*}$

aggression

Note: Parent education $1=$ less than high school, $6=$ graduate/professional degree. Sibling gender composition dummy coded so that brother-brother pairs are the reference group. Ethnicity dummy coded ( white $=1$ and other $=0$ ). Birth order dummy coded $(1=$ older and $0=$ younger $)$. $* \mathrm{p}<.05 ; * * \mathrm{p}<.01 ; * * * \mathrm{p}<.001$. 


\section{References}

Buist, K.L., Deković, M., \& Prinzie, P. (2013). Sibling relationship quality and psychopathology of children and adolescents: A meta-analysis. Clinical Psychology Review, 33, 97-106. doi: $10.1016 /$ j.cpr.2012.10.007

Caffaro, J.V. (2014). Sibling abuse trauma ( $2^{\text {nd }}$ edition). New York, NY: Routledge.

Crick, N.R., Ostrov, J.M., \& Werner, N.E. (2006). A longitudinal study of relational aggression, physical aggression, and children's psychosocial adjustment. Journal of Abnormal Child Psychology, 34, 131-142. doi: 10.1007/s10802-005-9009-4

Kreider, R.M. \& Ellis, R. (2011). Living arrangements of children: 2009. In Current Population Reports (pp. 70-126). Washington, DC: US Census Bureau

NICHD Early Childcare Research Network (2005). Nonmaternal care and family factors in early development: An overview of the NICHD Study of Early Childcare. New York: Guilford.

Ozer, E. \& Irwin, C. (2009). Adolescent and young adult health: From basic health status to clinical interventions. In R. Lerner \& L. Steinberg (Eds.), Handbook of adolescent psychology ( $3^{\text {rd }}$ ed., Vol1, pp. 618-641). New York: Wiley.

Roscoe, B., Goodwin, M. P., \& Kennedy, D. (1987). Sibling violence and agonistic interactions experienced by early adolescents. Journal of Family Violence, 2(2), 121-137. doi: 10.1007/BF00977037

Straus, M. A., Gelles, R. J., \& Steinmetz, S. K. (1980/2006). Behind closed doors: Violence in the American family. New York: Doubleday/Anchor Books.

Temcheff, C.E., Serbin, L.A., Martin-Storey, A., Stack, D.M., Ledingham, J., \& Schwartzman, A.E. (2011). Predicting adult physical health outcomes for childhood aggression, social withdrawal, and likeability: A 30-year prospective, longitudinal study. International Journal Behavioral Medicine, 18, 5-12. doi: 10.1007/s12529-010-9082-0 
Tucker, C.J., Finkelhor, D., Shattuck, A., \& Turner, H. (2013). Prevalence and correlates of sibling victimization types. Child Abuse \& Neglect, 37, 213-223. doi: 10.1016/j.chiabu.2013.01.006

Tucker, C. \& Kazura, K. (2013). Parental responses to sibling conflict of school-aged children. Journal of Child \& Family Studies, 22, 737-745. doi: 10.1007/s10826-013-9741-2

Wolke, D. \& Samara, M.M. (2004). Bullied by siblings: Association with peer victimization and behavior problems in Israeli lower secondary school children. Journal of Child Psychology and Psychiatry, 45, 1015-1029. doi: 10.1111/j.1469-7610.2004.t01-100293.x 